\title{
Damage Potential Prediction of Greek Earthquakes Based on Spectral Sustainability Measures Derived from 3-D Displacement Response Spectra: Part - I
}

\author{
P.K. Koliopoulos ${ }^{*}$ \\ Civil - Surveying \& Geomatics Engineering Dept., Technological Educational Institute of Central Macedonia, Serres, \\ Greece
}

\begin{abstract}
The aim of this work is the investigation of the correlation between seismic damage measures and the sustainability of response displacement peak, deduced from novel 3-D response spectra. These spectra are produced with relatively small additional computational cost compared to their 2-D counterparts and incorporate valuable additional information concerning the sustainability of conventional spectral values to the rest of major response cycles. The utilization of 3-D response spectra leads to the computation of handy sustainability indices, proposed herein, that reflect the sensitivity of standard response spectra values to (i) the number of significant response half-cycles ('transversal' sustainability index $\lambda_{1}$ ) and (ii) the elongation of fundamental elastic period due to inelastic response ('horizontal' sustainability index $\lambda_{2}$ ). Based on selected Greek ground motion records, a time domain inelastic dynamic analysis study was performed for elasto-plastic single degree of freedom (sdof) oscillators. The results reveal the strong correlation between the spectral sustainability indices and the damageability of each record and were utilized to produce empirical estimators as functions of the aforementioned sustainability indices, in order to serve as reliable predictors of standard damage indices. The applicability of the findings to a greater sample of ground motion records and more realistic structural systems (such as single and multi-storey plane RC frames) has been confirmed and will be presented in a forthcoming companion publication.
\end{abstract}

Keywords: 3-D response spectra, damage potential, elasto-plastic oscillators, sustainability measures.

\section{INTRODUCTION}

The importance of ground motion duration and frequency content for the determination of the damage potential of seismic action has been recognized and it is now well established within the scientific community. The fact that the conventional response spectra rely exclusively on a unique instantaneous peak, which may not be representative of the peak values of the rest response cycles, is probably the major reason for the often realised discrepancy between spectral ordinate values and damageability of excitation records. Indeed, the damage potential of the excitation is directly related to duration and the number of significant amplitude response half-cycles, contributing to low cycle damage [1-4]. Attempts to alleviate this drawback resulted in the implementation of 'effective' spectral values which are produced by empirical reduction factors.

Conversely, more rational approaches have been attempted and can be classified in two broad categories: (i) those employing energy related response spectra [5-8] and (ii) those remaining within the framework of conventional spectral quantities, but introducing extra dimensions, such as the concept of 3-D response spectra $[9,10]$. The latter approach provides a tool for distinction between excitation records with similar conventional 2-D response spectra but

*Address correspondence to this author at the Civil - Surveying \& Geomatics Engineering Dept., Technological Educational Institute of Central Macedonia, Serres, Greece; Tel: +30-23210-49267;

E-mail: kolio@teiser.gr with different duration and energy characteristics (resulting in different damage potential). This is achieved by considering the peaks of additional response cycles given that records of longer duration and narrow-band energy spectra tend to exhibit more persistent peaks.

In the years following the aforementioned early works however, the 3-D spectra approach has not been significantly developed towards the production of a more complete and practical framework. To this end, the concept of 3-D spectra is here revisited and the extraction of useful information, capable to be incorporated into a damage prediction methodology, is attempted.

\section{3-D DISPLACEMENT RESPONSE SPECTRA AND SUSTAINABILITY MEASURES OF SPECTRAL OR- DINATES}

As already mentioned, the 3-D spectrum evolves from the standard 2-D response spectrum by adding a $3^{\text {rd }}$ axis denoting the hierarchically ordered absolute maxima of the $2^{\text {nd }}$, $3^{\text {rd }}, 4^{\text {th }}$, etc response half-cycles. The half-cycles (instead of full cycles) are considered in order to account for the randomness and variability of realistic non-harmonic seismic responses.

In the following Figures, the 3-D response displacement spectrum of the longitudinal horizontal component of the Lefkas $(14 / 8 / 2003, \mathrm{Mw}=6.4)$ earthquake is presented (Fig. 1) and the spectral production process explained (Fig. 2). 


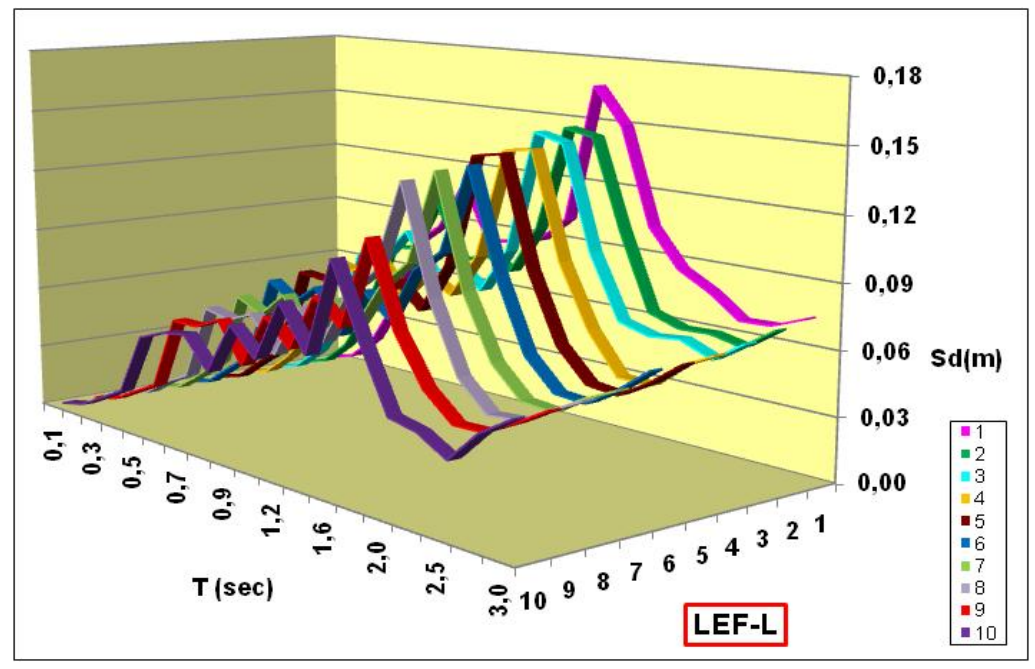

Fig. (1). 3-D elastic response displacement spectrum $(\xi=5 \%)$ of the LEF-L record (peaks of the top 10 response half-cycles).

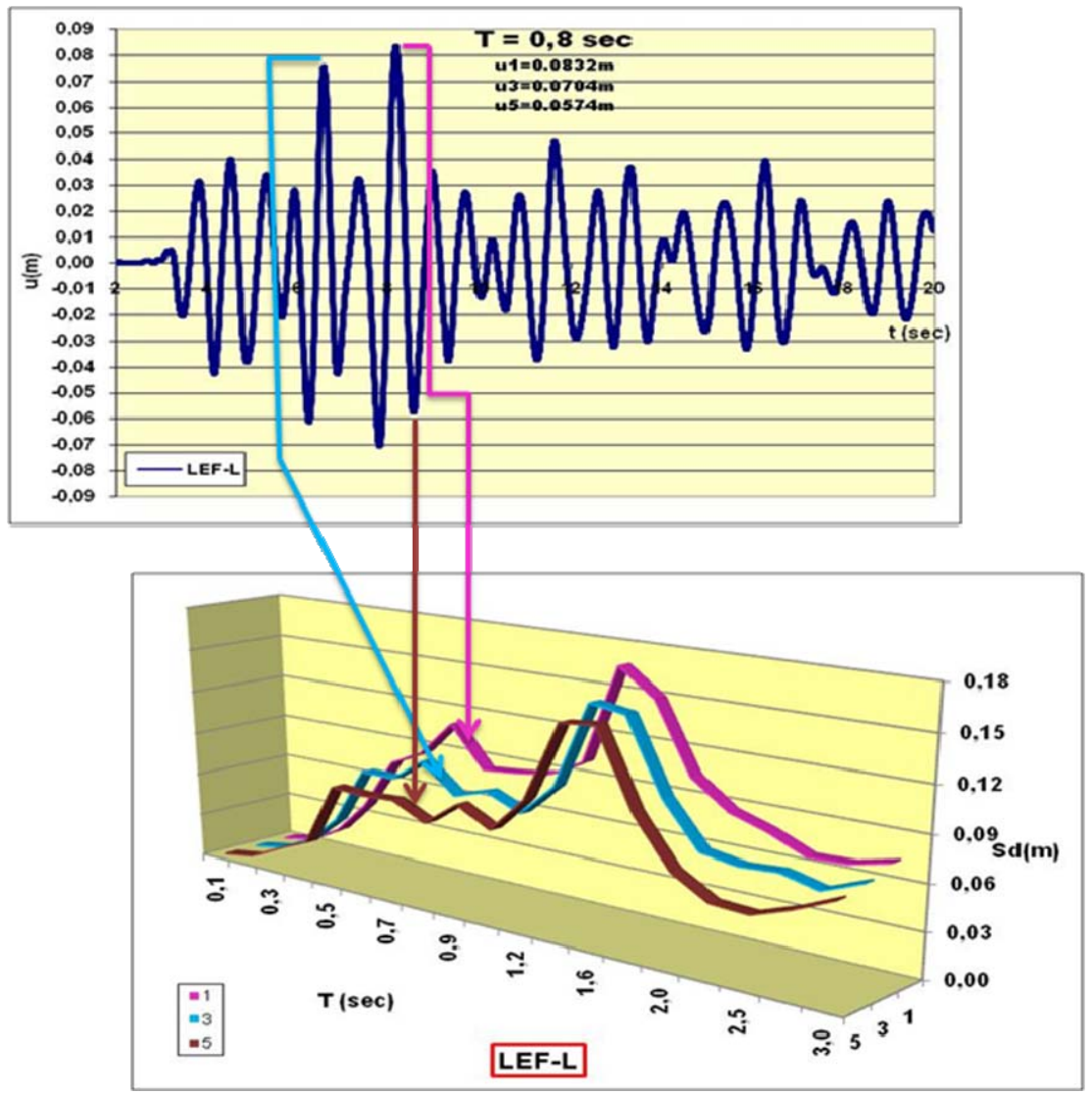

Fig. (2). Construction of the $3-D$ elastic response displacement spectrum $(\xi=5 \%)$ of the LEF-L record (peaks of the $1^{\text {st }}, 3^{\text {rd }}$ and $5^{\text {th }}$ top response half-cycles).

A practical way to extract the information provided by the 3-D spectral ordinates is to introduce sustainability indices. For a given value of the structural elastic period $\mathrm{T}=\mathrm{T}_{\mathrm{el}}$, two complementary spectral sustainability indices are introduced, in order to take into account two important factors related to the damage potential of structural response.
(A) The first factor is the rate of decay of peak values of the hieratically ordered significant half-cycles, even for the elastic response corresponding to $\mathrm{T}_{\mathrm{el}}$. This information is mainly related to fatigue failure (in the context of earthquake engineering is related to damage caused by dozens of strong aftershocks following major seismic events) and is easily 
extracted from the $3^{\text {rd }}$ 'transversal' axis added into the conventional 2-D spectrum. A convenient non-dimensional sustainability index $\lambda_{1}$ is defined as follows:

$$
\lambda_{1}(\mathrm{~T}, \mathrm{~N})=\frac{\sum_{\mathrm{j}=1}^{\mathrm{N}} \mathrm{S}_{\mathrm{j}}(\mathrm{T})}{\mathrm{N} \cdot \mathrm{S}_{1}}, 1 / \mathrm{N}<\lambda_{1}<1
$$

where: $S_{j}(T)$ is the peak of the $j^{\text {th }}$ hieratically ordered response half-cycle, $\mathrm{N}$ is the number of the significant halfcycles taken into account (typically $3-10$ ), $\mathrm{S}_{1}$ the maximum response peak (identical to the conventional 2-D spectral value).

The above definition corresponds to the mean value of the $\mathrm{N}$ peaks considered as a fraction of the maximum spectral value $S_{1}$ or (equivalently) as the ratio of the area along the ordinates of the $3^{\text {rd }}$ axis (decaying peak values) over the area of an orthogonal with a constant height equal to the maximum spectral value $S_{1}$. The lowest possible value of value of index $\lambda_{1}$ corresponds to a totally unrealistic case of a response consisting of only one significant half-cycle and $\mathrm{N}$ 1 cycles with negligible amplitudes. On the other hand, the maximum value of unity corresponds to an equally unrealistic case of a response with non decaying peaks, as it is the case of stationary harmonic excitation, at least for the $\mathrm{N}$ significant consisting half-cycles considered.

As an example, the index $\lambda_{1}$ of the LEF-L record mentioned above, is presented in (Fig. 3), for four values of the significant response cycles considered $(\mathrm{N}=3,5,7,9)$ and for a range of elastic periods between 0 and $2 \mathrm{sec}$. The fluctuation of sustainability, even for adjacent elastic periods, reflects the corresponding fluctuation of frequency content of the seismic action.

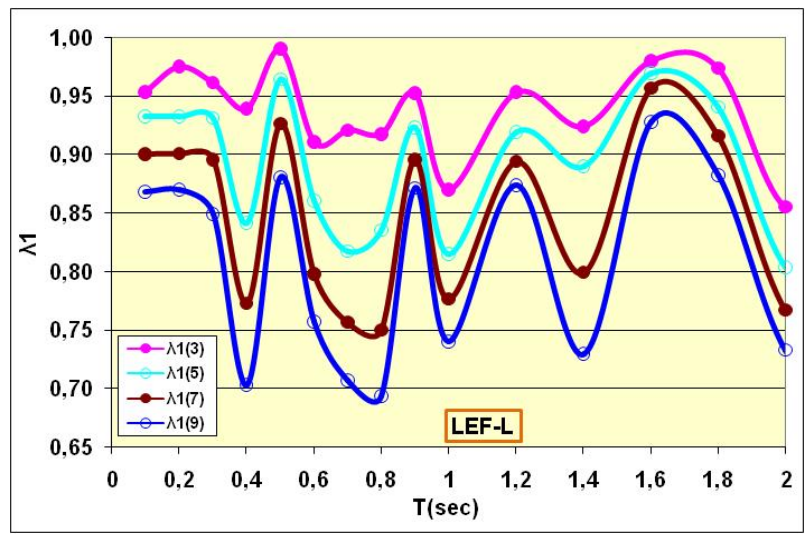

Fig. (3), Transversal sustainability index $\lambda_{1}(T, N)$ regarding the elastic response displacement spectrum $(\xi=5 \%)$ of the LEF-L record (taking into account up to $3^{\text {rd }}, 5^{\text {th }}, 7^{\text {th }}$, and $9^{\text {th }}$ top response halfcycles).

Clearly, the index $\lambda_{1}$ facilitates the distinction between two response cases, one with long duration and persistence of high secondary response peaks and another of short duration, exhibiting, perhaps, only one or two significant response cycles. Evidently, even if these two records share the same conventional spectral value $S_{1}$, the damage potential of the former is considerably larger than the potential of the latter; an important difference that is encapsulated in their respective spectral sustainability indices $\lambda_{1}$.

The above arguments (as it will be shown in the next sections) are confirmed via nonlinear dynamic analyses under recorded strong motion data. The usefulness of the 'transversal' index $\lambda_{1}$, however, is limited to linear or quasi-linear responses due to the fact that it is anchored to the elastic pe$\operatorname{riod} \mathrm{T}=\mathrm{T}_{\mathrm{el}}$. This observation leads to the introduction of a complementary sustainability index $\lambda_{2}$.

(B) The second factor relates to the relative change (increase or decrease) of spectral values due to elongation of the effective period, as the response gets into the nonlinear regime. Therefore, the system will be affected by the whole range of spectral values from the elastic period $T=T_{\text {el }}$ to the maximum elongated effective period $\mathrm{T}=\mathrm{T}_{\mu}$. This issue has already been introduced and explored based on conventional 2-D response acceleration spectra [e.g. 11,12]. In the context of the present work, the following 'horizontal' sustainability index $\lambda_{2}$ is introduced:

$$
\lambda_{2}(T, \mu)=\lambda_{2}\left(T_{e l}, T_{\mu}\right)=\frac{\sum_{1 \rightarrow T_{e l}}^{r \rightarrow T_{\mu}} S_{1}\left(T_{r}\right)}{r \cdot S_{1}\left(T_{e l}\right)}
$$

where: $T_{\mu}$ is the maximum elongated effective period (related to the target ductility $\mu$ ), $T_{\text {el }}$ is the initial elastic period, $\mathrm{S}_{1}\left(\mathrm{~T}_{\mathrm{r}}\right)$ is the conventional spectral value corresponding to a period $T_{e l} \leq T_{r} \leq T_{\mu}$ and $r$ is the number of discretization points between $T_{e l}$ and $T_{\mu}$. Obviously, the above index is valid for $\mu \geq 1.0$ and equals to unity for $\mu=1.0$

The following clarifications are due, regarding index $\lambda_{2}$ :

(i) Equation (2) is a simpler version of a more elaborate sustainability index $\lambda_{2}[13,14]$ which takes into account the influence of the transversal sustainability of the spectral values for the whole range of elongated periods considered.

(ii) A wide range of empirical expressions are found in the literature regarding the relation between the maximum elongated period and ductility. Herein, elasto-plastic oscillators are considered and thus, the simple expression $\left(\mathrm{T}_{\mu} / \mathrm{T}_{\mathrm{el}}\right)^{2}$ $=\mu,[15]$, is adopted.

(iii) The influence of the increased damping due to the nonlinear response can be taken into account via modification (reduction) of spectral values. This can be achieved implementing either simple code-defined reduction factors or more advanced empirical expressions found in the literature [e.g. 16]. The issue will not be considered herein, because the derived empirical predictors are based on results of nonlinear (but non-hysteretic) dynamic analyses which are affected by the increased damping.

The variation of index $\lambda_{2}$ of the LEF-L record is presented in (Fig. 4), for a range of elastic periods between $0.4 \mathrm{~s}$ and $1.0 \mathrm{~s}$ and for an elongated period up to 3 times the elastic one. The range of the corresponding approximate values of ductility factor is $1 \leq \mu \leq 9$. As expected for displacement spectra, there is a general tendency for increased spectral values $\left(\lambda_{2}>1.0\right)$ as the maximum elongated effective period increases. It is worth noting that the rapid increase of spectral ordinates between $T=0.4 \mathrm{sec}$ and $T=1.0 \mathrm{sec}$ (Figs. $1 \&$ 2) is reflected to the high values of the corresponding index 
$\lambda_{2}$ for $T_{\mathrm{el}}=0.4 \mathrm{sec}$ and $\mathrm{T}_{\mu} / \mathrm{T}_{\mathrm{el}} \leq 3.0$. The increase is less significant for higher period values, because the starting spectral values $\mathrm{S}_{1}\left(\mathrm{~T}_{\mathrm{el}}\right)$ are higher (larger denominator for index $\lambda_{2}$ ). Due to a 'temporal' decrease of of spectral ordinates between $\mathrm{T}=0.7 \mathrm{sec}$ and $\mathrm{T}=1.5 \mathrm{sec}$ (Figs. $1 \& 2$ ), the corresponding index $\lambda_{2}$ for $\mathrm{T}_{\mathrm{el}}=0.7 \mathrm{sec}$ and $\mathrm{T}_{\mu} / \mathrm{T}_{\mathrm{el}} \leq 2.1$ is less than one.

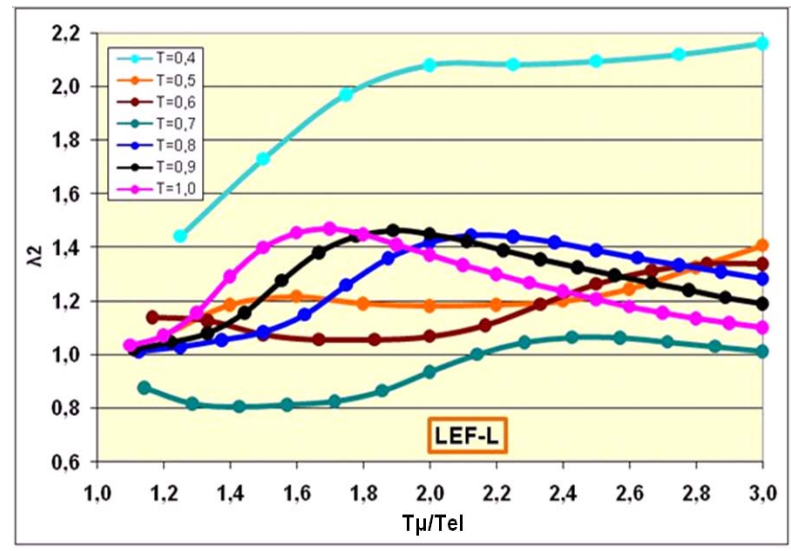

Fig. (4). Horizontal sustainability index $\lambda_{2}(T, \mu)$ regarding the elastic response displacement spectrum $(\xi=5 \%)$ of the LEF-L record for a range of elastic periods $0.4 \mathrm{sec} \leq \mathrm{T}_{\mathrm{el}} \leq 1.0 \mathrm{sec}$.

\section{CORRELATION BETWEEN SUSTAINABILITY MEASURES AND COMMON GLOBAL DAMAGE PREDICTORS}

In order to demonstrate the correlation of the proposed spectral sustainability indices $\lambda_{1}$ and $\lambda_{2}$ with widely accepted global damage measures, the response of 3 elasto-plastic sdof oscillators with elastic periods $T_{\text {el }}=0.2,0.5$ and $0.8 \mathrm{sec}$, for a range of reduction factors $1.2 \leq \mathrm{q}=\mathrm{V}_{\mathrm{el}} / \mathrm{V}_{\mathrm{y}} \leq 3.0$, subjected to 2 strong ground motion records is computed and compared. The selected accelerograms include the LEF-L record presented above and the A399-L record of Athens $(7 / 9 / 1999, \mathrm{Mw}=6)$ earthquake. In order to focus on the importance of the spectral sustainability, the A399-L record was scaled (separately for each elastic period), in order to match the elastic displacement spectrum of the LEF-L record. Therefore, from a conventional elastic spectrum perspective, the damageability of the 2 excitations is identical.

In the parametric analyses performed, two global damage indices are adopted for the scalar quantification of damage. The first is the widely accepted Park \& Ang damage index $[17,18]$, which is here implemented in the form of [19]:

$$
D_{\mathrm{PA}}=\frac{\delta_{\mathrm{dem}}-\delta_{\mathrm{y}}}{\delta_{\text {sup }}-\delta_{\mathrm{y}}}+\beta \frac{\mathrm{E}_{\mathrm{h}}}{\mathrm{F}_{\mathrm{y}}\left(\delta_{\text {sup }}-\delta_{\mathrm{y}}\right)}
$$

where, $\beta$ is the Park \& Ang parameter (typically 0.10$0.15), \mathrm{F}_{\mathrm{y}}$ and $\delta_{\mathrm{y}}$ are the yield force and yield displacement respectively, $\mathrm{E}_{\mathrm{h}}$ is the cumulative plastic energy, $\delta_{\mathrm{dem}}$ and $\delta_{\text {sup }}$ are the demand and supply displacements respectively.

Due to the fact that the quantity $\delta_{\text {sup }}$ is not uniquely defined because it depends on the specific characteristics of the structural system, equation (3) is recasted in the following generalized form [20]:

$$
D_{\text {PA }}^{*}=\left[\frac{\delta_{\text {sup }}}{\delta_{\mathrm{y}}}-1\right] \cdot D_{\mathrm{PA}}=\left(\mu_{\text {sup }}-1\right) \cdot \mathrm{D}_{\mathrm{PA}}=(\mu-1)+\beta \frac{\mathrm{E}_{\mathrm{h}}}{\mathrm{F}_{\mathrm{y}} \delta_{\mathrm{y}}}
$$

where, $\mu$ is the displacement ductility factor.

In engineering practice as well as in many code provisions, however, damage is often solely associated with drift or global displacement ductility factor $\mu$ [21]. It is convenient therefore, to introduce the following equivalent (damage-based) global ductility factor $\mu_{\mathrm{DI}}$ which corresponds to an effective displacement that alone (with no plastic energy component) would produce the same damage as the one predicted by eq. (4).

$$
\mu^{*}{ }_{\mathrm{DI}}=1+\mathrm{D}_{\mathrm{PA}}
$$

Clearly, $\mu^{*} \mathrm{DI} / \mu \geq 1$ while, large deviations from unity indicate significant contribution of the cumulative plastic energy into the global structural damage. This, in turn, is mainly attributed to long duration and high amplitude response cycles or (in the context of present work) to increased spectral sustainability.

\subsection{The $T_{e l}=0.5 \sec$ Case}

Starting with the response of the oscillator with elastic period $\mathrm{T}_{\mathrm{el}}=0.5 \mathrm{sec}$, a comparison of the elastic response histories shown in (Fig. 5) reveals the superior transversal sustainability of the LEF-L record over the scaled A399-L record (both share the same maximum displacement equal to $75.9 \mathrm{~mm}$ ). This difference is more clearly captured in Table $\mathbf{1}$ where the values of the ordered peak values of the top 10 response half-cycles and the corresponding 'transversal' sustainability indices $\lambda_{1}$ are reported.

The sustainability dominance of LEF-L over the scaled A399-L is expected to result in higher damage indices (eqs. 4 and 5) for small to mild nonlinear behavior (small values of $\mathrm{q}$ and $\mu$ ), with effective period $\mathrm{T}_{\mu}$ close to the elastic pe$\operatorname{riod} \mathrm{T}_{\mathrm{el}}$. This restriction stems from the fact that 'transversal' sustainability is computed from spectral ordinates associated with the elastic period.

Indeed, Fig. (6) shows that for a small value of reduction factor $\mathrm{q}=1.25$, the LEF-L record causes double as much damage as the damage related to the scaled A399-L record. The damage indices, also shown in (Fig. 6), are computed based on eq. 4 with a Park \& Ang parameter $\beta=0.10$. Higher values of $\beta$ would predict even greater damageability for LEF-L, emphasizing the importance of repeated highamplitude response half-cycles (increased sustainability).

However, as q increases - corresponding to higher ductility factors $\mu$ and significant departure of the effective period $\mathrm{T}_{\mu}$ from $\mathrm{T}_{\mathrm{el}}$ - the situation is reversed. Gradually (Figs. $7 \&$ 8), the two records produce comparable damage and after a certain point the A399-L record exhibits greater damageability than the LEF-L one.

The above mentioned reversal can be explained by referring to the 'horizontal' spectral sustainability of the two ground motion records. As it is manifested from the variation of the corresponding sustainability indices $\lambda_{2}$ (shown in Fig. 9), the A399-L record exhibits significantly greater sustainability throughout a range of period elongation $T_{\mu} / T_{e l}=1.2-$ 2.4 , while this difference is gradually reduced for values $\mathrm{T}_{\mu} / \mathrm{T}_{\mathrm{el}}=2.5-3.0$. 


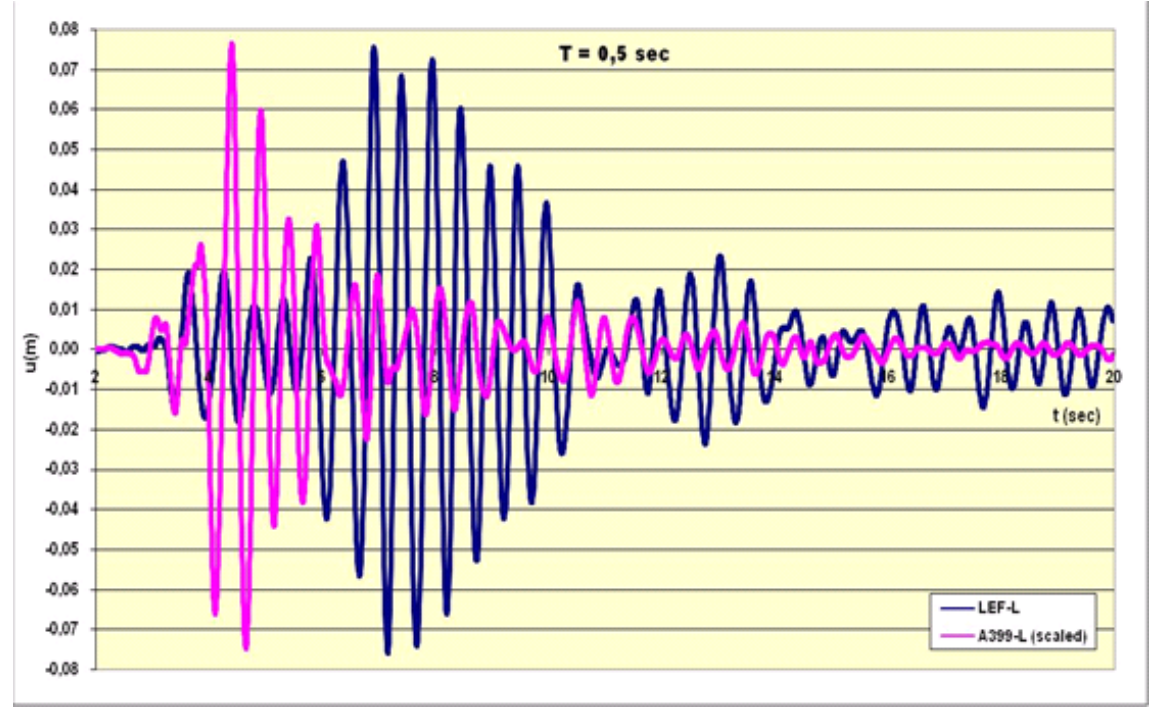

Fig. (5). Elastic response time histories for a sdof $\left(T_{\mathrm{el}}=0.5 \mathrm{sec}, \xi=5 \%\right)$ oscillator subjected to the LEF-L (blue) and scaled A399-L (pink) records.

Table 1. 'Transversal' sustainability indices $\lambda_{1}$ for $(T=0.5 \mathrm{sec}, \xi=5 \%)$ oscillator subjected to the LEF-L and scaled A399-L records.

\begin{tabular}{|c|c|c|c|c|}
\hline & LEF-L & A399-L & LEF-L & A399-L \\
\hline $\mathbf{J}$ & $\mathbf{S d}_{\mathbf{j}}(\mathbf{c m})$ & $\mathbf{S d}_{\mathbf{j}}(\mathbf{c m})$ & $\boldsymbol{\lambda}_{\mathbf{1}}$ & 1.00 \\
\hline $\mathbf{1}$ & 7.59 & 7.59 & 0.997 & 0.989 \\
\hline $\mathbf{2}$ & 7.54 & 7.42 & 0.990 & 0.948 \\
\hline $\mathbf{3}$ & 7.42 & 6.57 & 0.981 & 0.906 \\
\hline $\mathbf{4}$ & 7.23 & 5.94 & 0.965 & 0.841 \\
\hline $\mathbf{5}$ & 6.83 & 4.40 & 0.949 & 0.784 \\
\hline $\mathbf{6}$ & 6.61 & 3.80 & 0.927 & 0.733 \\
\hline $\mathbf{7}$ & 6.01 & 3.22 & 0.904 & 0.692 \\
\hline $\mathbf{8}$ & 5.65 & 3.06 & 0.881 & 0.653 \\
\hline $\mathbf{9}$ & 5.29 & 2.59 & 0.855 & 0.617 \\
\hline
\end{tabular}

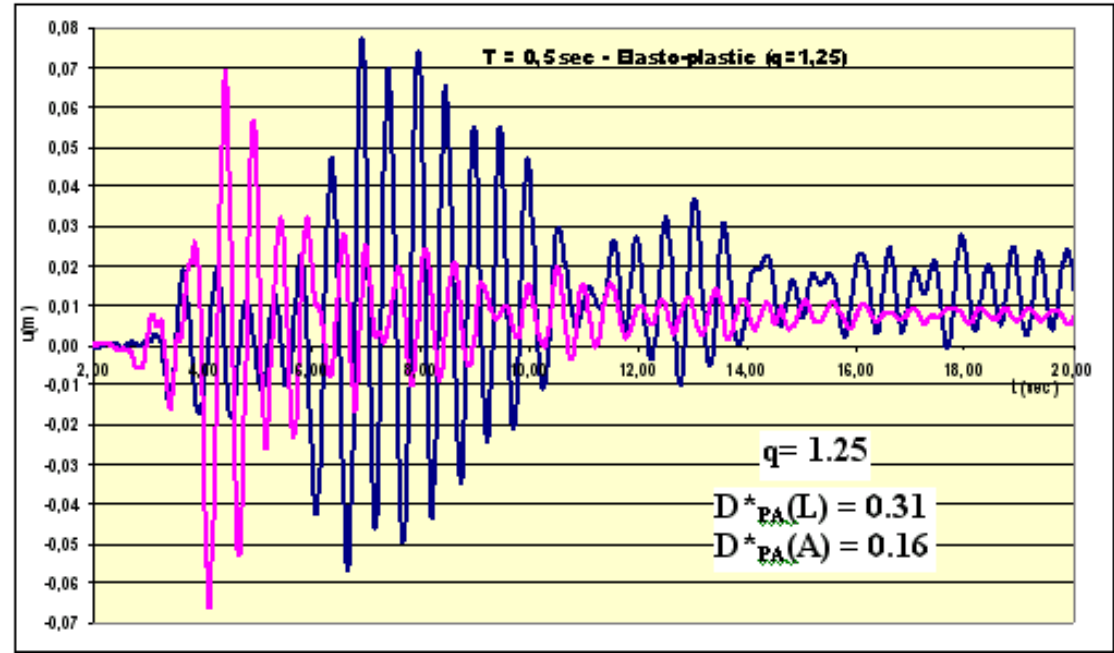

Fig. (6). Elasto-plastic response time histories and damage indices, for a sdof $\left(\mathrm{T}_{\mathrm{el}}=0.5 \mathrm{sec}, \xi=5 \%\right)$ oscillator subjected to the LEF-L (blue) and scaled A399-L (pink) records. 


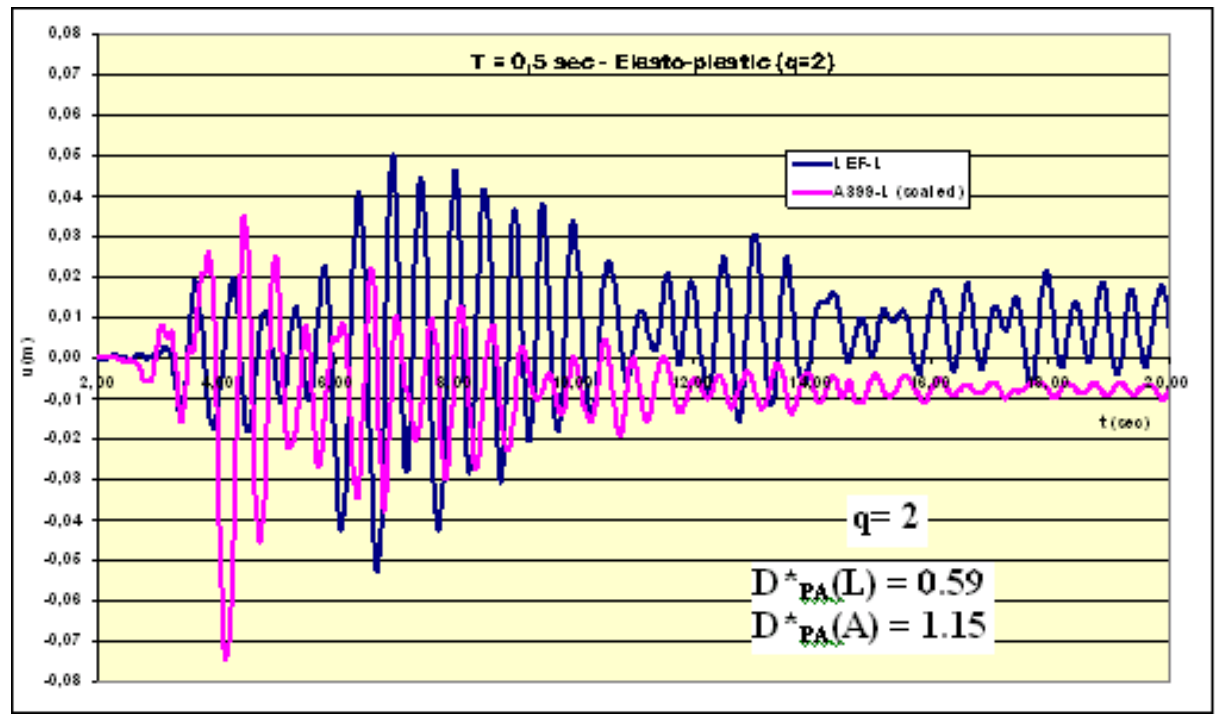

Fig. (7). Elasto-plastic response time histories and damage indices, for a sdof ( $\mathrm{T}_{\mathrm{el}}=0.5 \mathrm{sec}, \xi=5 \%$ ) oscillator subjected to the LEF-L (blue) and scaled A399-L (pink) records.

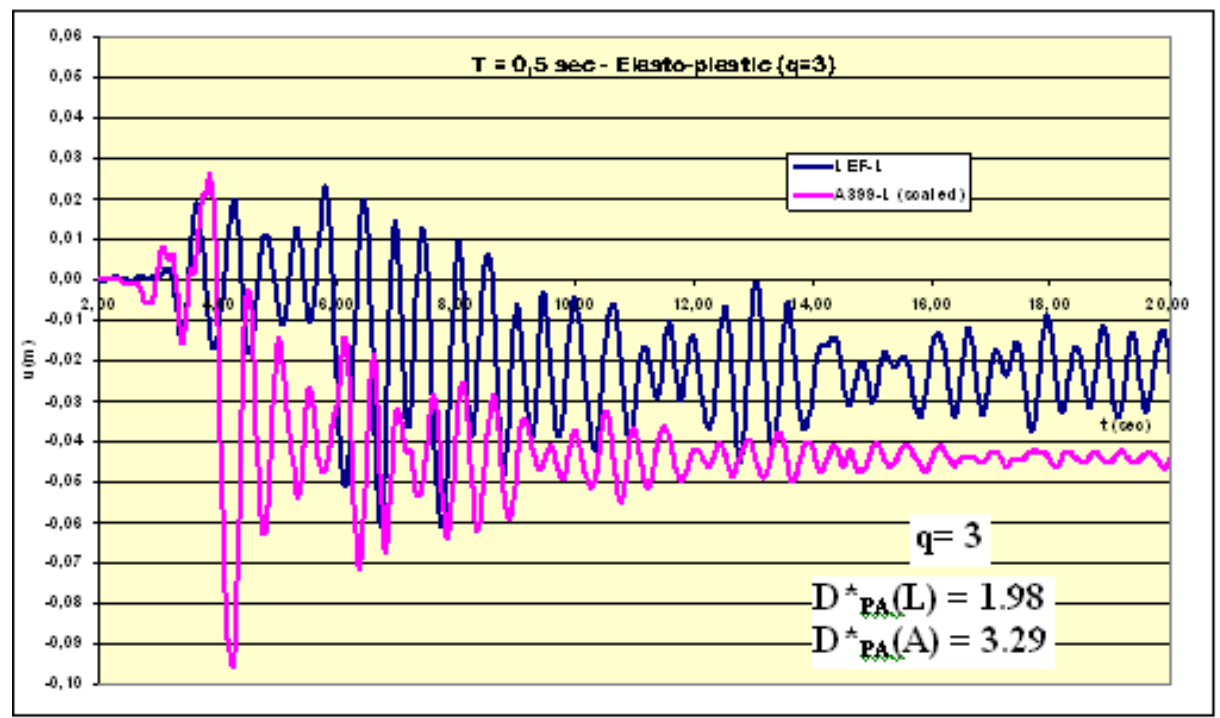

Fig. (8). Elasto-plastic response time histories and damage indices, for a sdof $\left(\mathrm{T}_{\mathrm{el}}=0.5 \mathrm{sec}, \xi=5 \%\right)$ oscillator subjected to the LEF-L (blue) and scaled A399-L (pink) records.

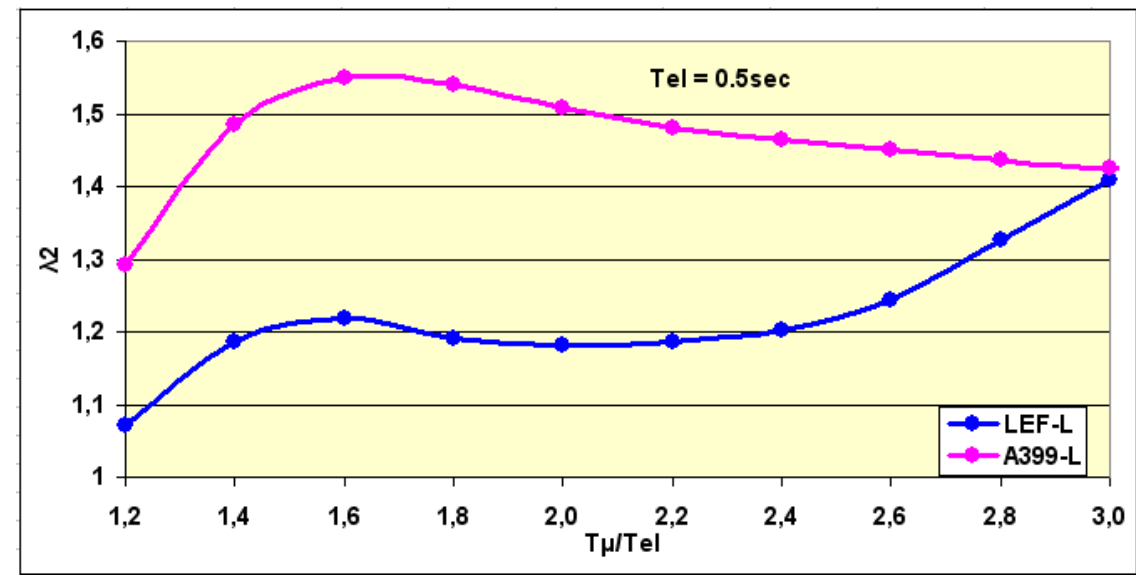

Fig. (9). Horizontal sustainability indices $\lambda_{2}(T, \mu)$ for a sdof $\left(T_{\mathrm{el}}=0.5 \mathrm{sec}, \xi=5 \%\right)$ oscillator subjected to the LEF-L (blue) and scaled A399-L (pink) records. 
It is not surprising, therefore, that for strong nonlinear behaviour the influence of 'transversal' sustainability diminishes and the 'horizontal' sustainability takes over in determining the structural response. It turns out that for values of reduction factor $\mathrm{q}$ greater than 1.5 , the damageability of A399-L record increases in a much faster rate than that of the LEF-L record as manifested in the following (Fig. 10).

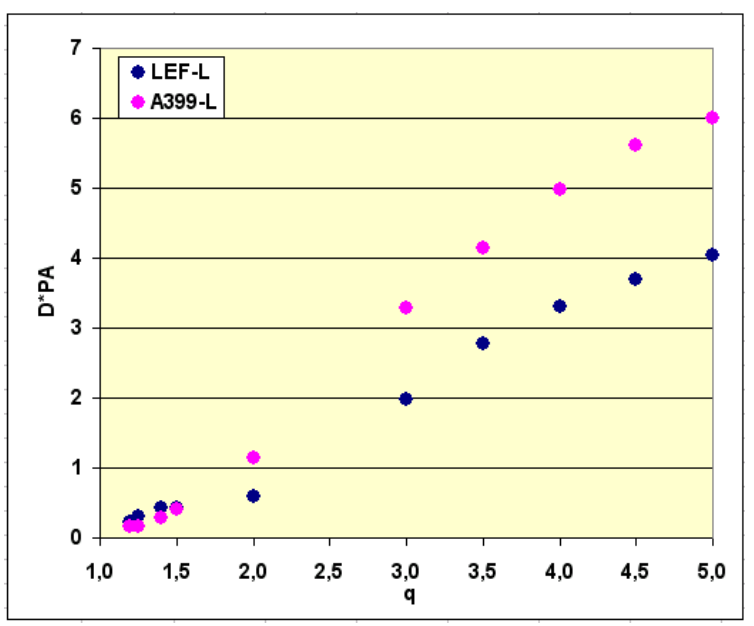

Fig. (10). Damage indices (eq. 4), for a sdof $\left(\mathrm{T}_{\mathrm{el}}=0.5 \mathrm{sec}, \xi=5 \%\right)$ oscillator subjected to the LEF-L (blue) and scaled A399-L (pink) records.

\subsection{The $T_{\mathrm{el}}=0.2 \mathrm{sec}$ and $T_{\mathrm{el}}=0.8 \mathrm{sec}$ Cases}

The strong correlation between damage potential and the spectral sustainability indices $\lambda_{1}$ and $\lambda_{2}$, is further confirmed from the findings of the computed elasto-plastic response of oscillators with elastic periods $\mathrm{T}_{\mathrm{el}}=0.2 \mathrm{sec}$ and $\mathrm{T}_{\mathrm{el}}=0.8 \mathrm{sec}$, under the LEF-L and scaled A399-L records, for a range of reduction factors $\mathrm{q}$.

Starting with the $\mathrm{T}_{\mathrm{el}}=0.2 \mathrm{sec}$ case, the superior transversal sustainability of the LEF-L record over the scaled A399$L$ record (both share the same maximum displacement equal to $5.2 \mathrm{~mm}$ ), is clearly supported by both the elastic response records in (Fig. 11) and the following Table 2 with the top 10 ordered peak values of response half-cycles and the corresponding 'transversal' sustainability indices $\lambda_{1}$.

The examination of the 'horizontal' spectral sustainability reveals that in this case, the dominance of LEFL record is preserved, as shown in (Fig. 12). where the computed 'horizontal' sustainability indices $\lambda_{2}$ covering a range of period elongation $\mathrm{T}_{\mu} / \mathrm{T}_{\mathrm{el}}=1.2-3.0$, are compared.

The superior spectral sustainability of LEF-L record in both 'transversal' and 'horizontal' sense, is in full accordance with the damage potential of the two records as expressed by the computed damage indices, shown in (Fig. 13).

Concluding this section, the $\mathrm{T}_{\mathrm{el}}=0.8 \mathrm{sec}$ case is examined. In this case, a reversed scenario from the $\mathrm{T}_{\mathrm{el}}=0.5 \mathrm{sec}$ case is realized. Now it is the scaled A399-L record that exhibits superior transversal sustainability over the LEF-L record, as shown in the elastic response records (Fig. 14) and from the top 10 ordered peak values and the corresponding 'transversal' sustainability indices $\lambda_{1}$, (Table 3 ).

Regarding the 'horizontal' spectral sustainability, however, the order is reversed and it is the LEF-L record that exhibits superior sustainability than the A399-L record. This is clearly manifested from the variation of the corresponding sustainability indices $\lambda_{2}$ (shown in Fig. 15). As a result, for values of reduction factor q greater than 2.0, the damageability of LEF-L record increases in a much faster rate than that of the scaled A399-L record, as manifested in (Fig. 16).

\section{EMPIRICAL DAMAGE PREDICTORS BASED ON THE SUSTAINABILITY INDICES $\Lambda_{1}$ AND $\Lambda_{2}$}

In the preceding section 3 , the strong correlation between the novel sustainability indices proposed herein and the computed damage indices for simple elasto-plastic oscillators has been demonstrated. The presented cases, selected

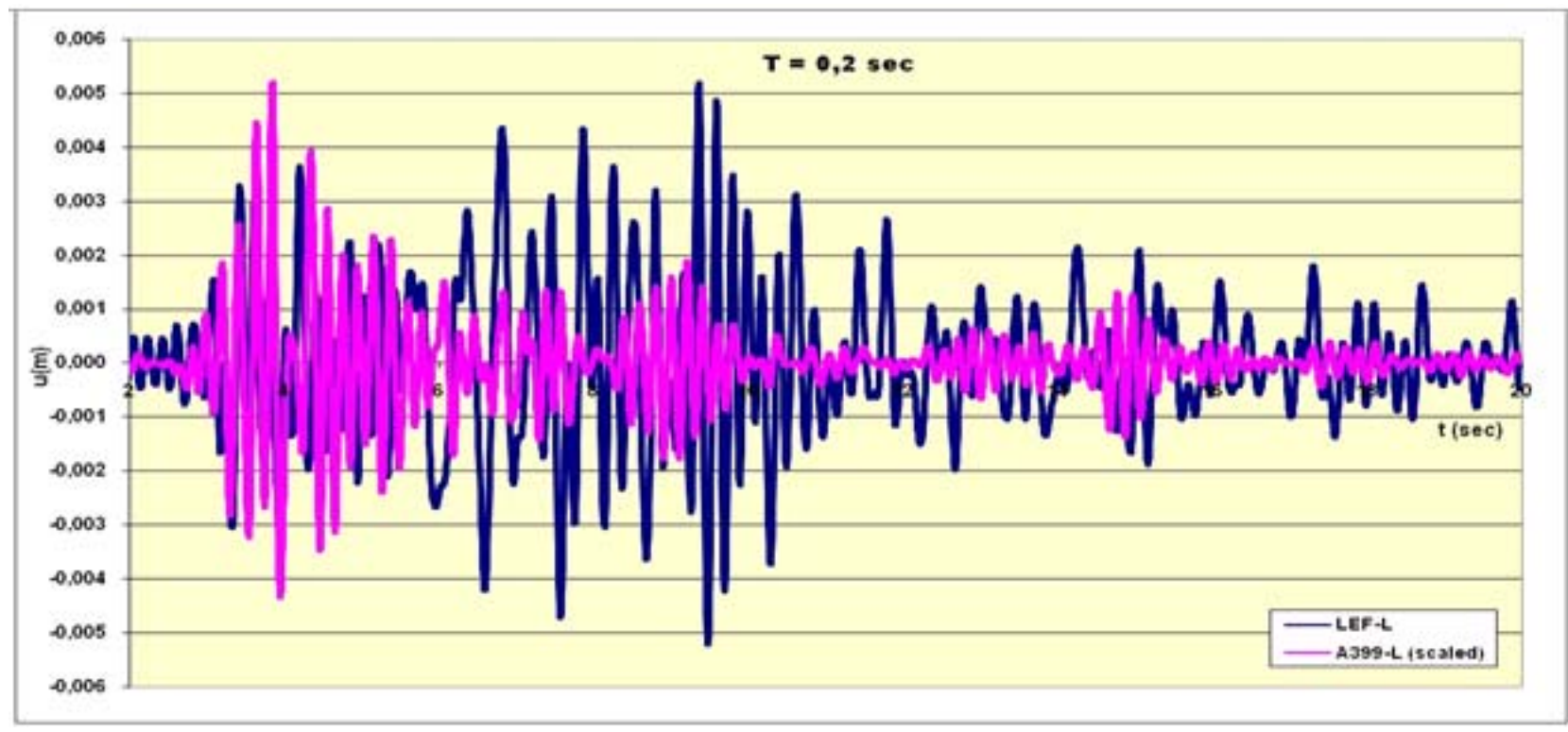

Fig. (11). Elastic response time histories for a sdof $(T=0,2 \mathrm{sec}, \xi=5 \%)$ oscillator subjected to the LEF-L and A399-L records. 
Table 2. 'Transversal' sustainability indices $\lambda_{1}$ for $(T=0.2 s e c, \xi=5 \%)$ oscillator subjected to the LEF-L and scaled A399-L records.

\begin{tabular}{|c|c|c|c|c|}
\hline & LEF-L & A399-L & LEF-L & A399-L \\
\hline $\mathbf{j}$ & $\mathrm{Sd}_{\mathrm{j}}(\mathrm{cm})$ & $\mathrm{Sd}_{\mathrm{j}}(\mathrm{cm})$ & $\lambda_{1}$ & $\lambda_{1}$ \\
\hline 1 & 0,52 & 0,52 & 1,000 & 1,000 \\
\hline 2 & 0,52 & 0,44 & 0,997 & 0,927 \\
\hline 3 & 0,49 & 0,43 & 0,975 & 0,895 \\
\hline 6 & 0,43 & 0,32 & 0,916 & 0,787 \\
\hline 7 & 0,42 & 0,31 & 0,901 & 0,761 \\
\hline 8 & 0,42 & 0,29 & 0,889 & 0,734 \\
\hline 9 & 0,37 & 0,28 & 0,870 & 0,713 \\
\hline
\end{tabular}

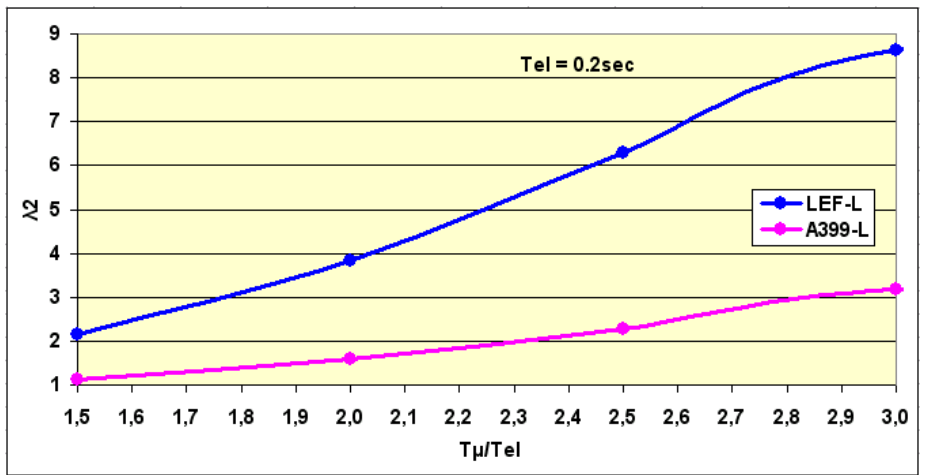

Fig. (12). Horizontal sustainability indices $\lambda_{2}(T, \mu)$ for a sdof $\left(T_{\text {el }}=0.2 \mathrm{sec}, \xi=5 \%\right)$ oscillator subjected to the LEF-L (blue) and scaled A399L (pink) records.

from a wider sample [14] confirmed that this correlation remains strong both for cases of invariable (for all values of q) superiority in damage potential of one record over the other $\left(\mathrm{T}_{\mathrm{el}}=0.2 \mathrm{sec}\right)$ and for cases exhibiting interchange of the order of damageability between the two records, as the reduction factor $\mathrm{q}$ varies $\left(\mathrm{T}_{\mathrm{el}}=0.5 \mathrm{sec}\right.$ and $\mathrm{T}_{\mathrm{el}}=0.8 \mathrm{sec}$, $)$.

It is worth noting that the information captured in the proposed sustainability indices is available within the standard computational scheme for the production of conventional 2-D elastic spectra, but is (unfortunately) disregarded. Yet, as discussed above, it can be very useful for the understanding nonlinear behaviour and damage potential.

Naturally, the next step is to consider whether the sustainability indices can be utilised for a quantitative estimation of expected damage. To this end, the following empirical relations are proposed, exploiting results from the parametric analyses of the wider sample mentioned above (comprising 16 ground motion records, 5 values of reduction factor $\mathrm{q}$ and 6 values of elastic period $\mathrm{T}_{\mathrm{el}}$ ).

For periods corresponding to the equal energy range, the proposed empirical predictors of the damage indices defined in Eqs. (4) and (5), are:

$$
\mathrm{D}^{*}{ }_{\mathrm{PA}}=(\mu-1) \cdot \lambda_{1}^{1 / \mu} \cdot \lambda_{2} \quad \mu^{*}{ }_{\mathrm{DI}}=1+\mathrm{D}^{*}{ }_{\mathrm{PA}}
$$

where, $\lambda_{1}$ and $\lambda_{2}$ are defined in eqs. (1) and (2). According to the remarks following eq. 2 , the utilization of the simpler version of 'horizontal' sustainability index $\lambda_{2}$ is utilised. The suggested predictors are valid for $\mu \geq 1.0$ and obviously predict no damage for $\mu=1.0$. Furthermore, they reflect the main observations made in section 3 . Namely:

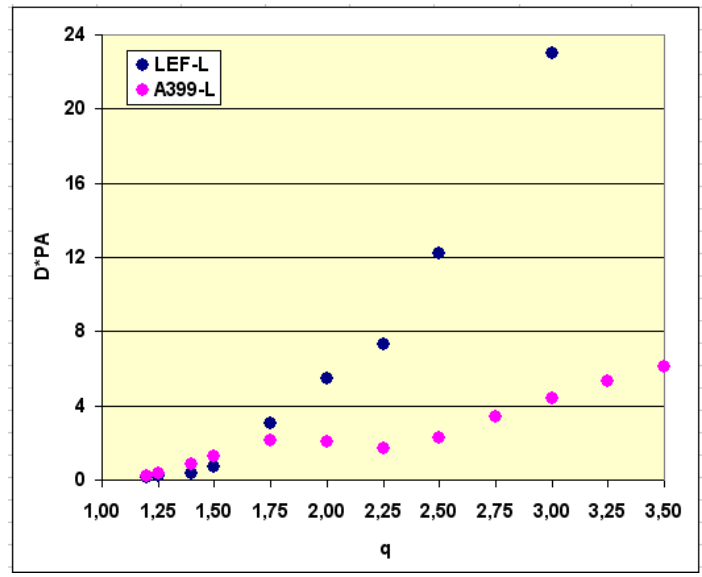

Fig. (13). Damage indices (eq. 4), for a sdof $\left(\mathrm{T}_{\mathrm{el}}=0.2 \mathrm{sec}, \xi=5 \%\right)$ oscillator subjected to the LEF-L (blue) and scaled A399-L (pink) records. 


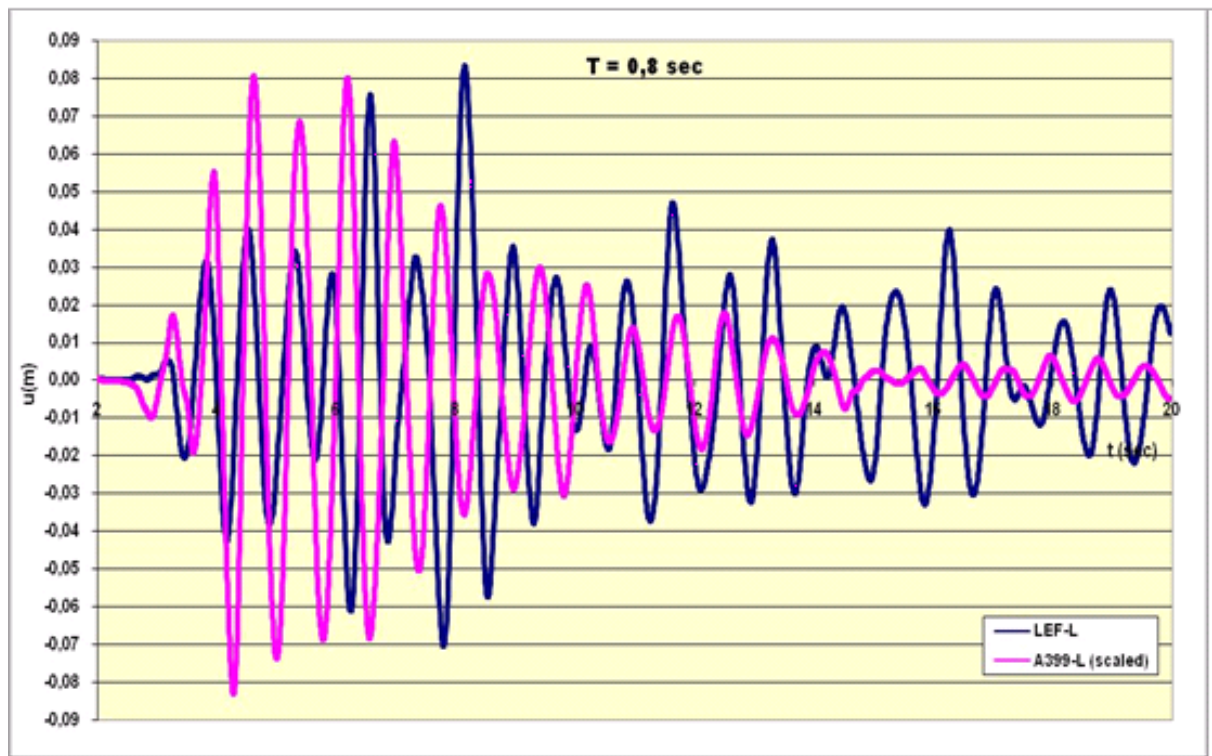

Fig. (14). Elastic response time histories for a sdof $(T=0.8 \mathrm{sec}, \xi=5 \%)$ oscillator subjected to the LEF-L and A399-L records.

Table 3. 'Transversal' sustainability indices $\lambda_{1}$ for $(T=0.8 s e c, \xi=5 \%)$ oscillator subjected to the LEF-L and scaled A399-L records.

\begin{tabular}{|c|c|c|c|c|}
\hline & LEF-L & A399-L & LEF-L & $\boldsymbol{\lambda}_{\mathbf{1}}$ \\
\hline $\mathbf{j}$ & $\mathbf{S d}_{\mathbf{j}}(\mathbf{c m})$ & $\mathbf{S d}_{\mathbf{j}} \mathbf{( \mathbf { c m } )}$ & 1,000 & $\boldsymbol{\lambda}_{\mathbf{1}}$ \\
\hline $\mathbf{1}$ & 8,32 & 8,32 & 0,953 & 1,000 \\
\hline $\mathbf{2}$ & 7,55 & 8,04 & 0,918 & 0,983 \\
\hline $\mathbf{3}$ & 7,05 & 7,99 & 0,872 & 0,953 \\
\hline $\mathbf{4}$ & 6,11 & 7,37 & 0,835 & 0,927 \\
\hline $\mathbf{5}$ & 5,74 & 6,87 & 0,790 & 0,910 \\
\hline $\mathbf{6}$ & 4,68 & 6,84 & 0,750 & 0,897 \\
\hline $\mathbf{8}$ & 4,26 & 6,82 & 0,720 & 0,879 \\
\hline $\mathbf{9}$ & 4,26 & 6,31 & 0,694 & 0,855 \\
\hline
\end{tabular}

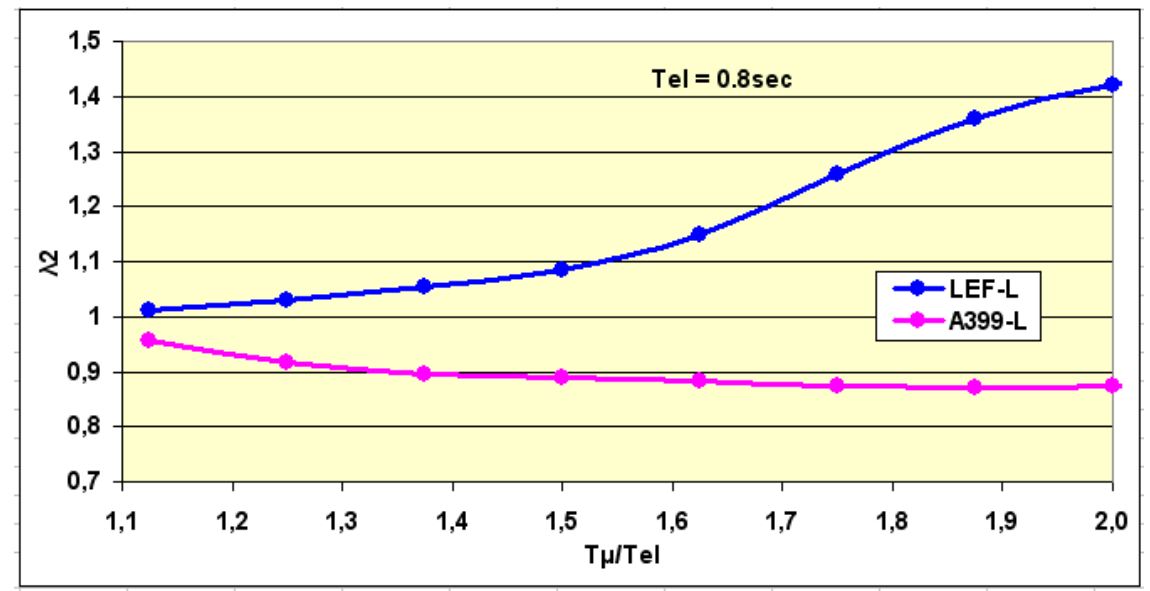

Fig. (15). Horizontal sustainability indices $\lambda_{2}(T, \mu)$ for a sdof $\left(T_{e l}=0.8 \sec , \xi=5 \%\right)$ oscillator subjected to the LEF-L (blue) and scaled A399$\mathrm{L}$ (pink) records. 


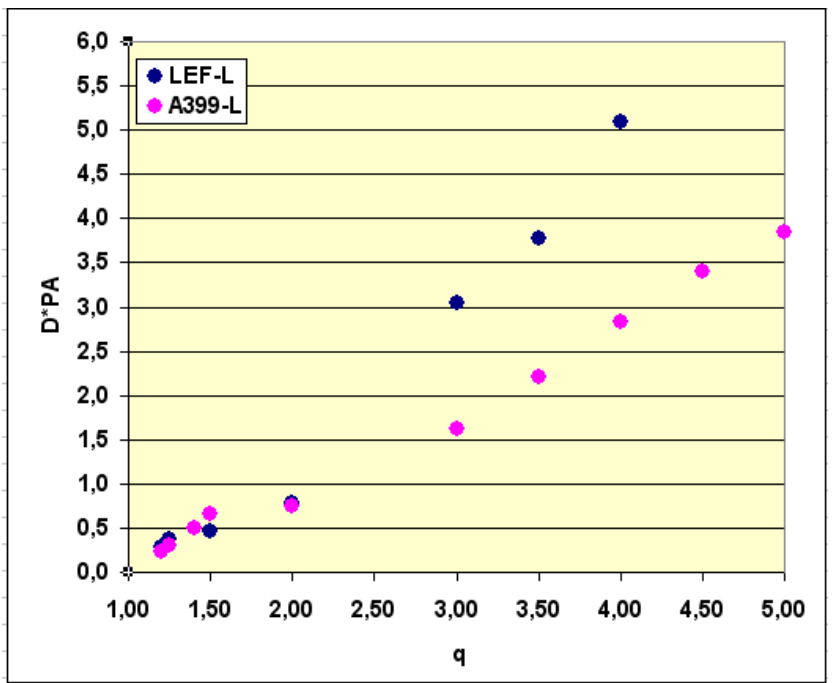

Fig. (16). Damage indices (eq. 4), for a sdof $\left(\mathrm{T}_{\mathrm{el}}=0.8 \mathrm{sec}, \xi=5 \%\right)$ oscillator subjected to the LEF-L (blue) and scaled A399-L (pink) records.

(i) For large values of $\mu$ the role of 'transversal' sustainability index $\lambda_{1}$ (anchored to the elastic period) is reduced and it is the 'horizontal' sustainability index $\lambda_{2}$ that controls the damage estimation.

(ii) Given that the 'horizontal' sustainability index $\lambda_{2}$ (eq. 2), is in fact a function of period elongation and $\mu$, it tends to unity for small values of $\mu$. Hence, it is the 'transversal' sustainability index $\lambda_{1}$ that controls damage for quasielastic response. Finally, given that the predictors stem from computational results, the role of increased damping due to nonlinearity is automatically taken into account.

For periods corresponding to the equal displacement range, the proposed empirical predictors are:

$$
\mathrm{D}^{*}{ }_{\mathrm{PA}}=\sqrt{(\mathrm{i}-1)} \cdot \lambda_{1}^{1 / \mu} \cdot \lambda_{2} \quad \mu_{\mathrm{DI}}^{*}=1+\mathrm{D}_{\mathrm{PA}}^{*}
$$

In practice, the implementation of eq. 6 for damage prediction requires a relationship between expected ductility $\mu$ and reduction factor q. This issue has been the topic of much research effort and various approximate expressions between the reduction factor, the ductility and elastic period can be found in the literature [e.g. 22, 23]. Here, the following expressions are employed because, despite their simplicity, provide reasonably accurate results [24].

$$
q=(\mu-1) \cdot \frac{T_{e l}}{T_{C}}+1 \text { for } T_{e l} \leq T_{C} \text { and } q=\mu \text { for } T_{e l}>T_{C}
$$

where, $\mathrm{T}_{\mathrm{C}}$ is the characteristic period of the ground motion. It is typically defined as the transition period where the constant acceleration segment of the response spectrum passes to the constant velocity segment of the spectrum. In the context of the present work, a constant value of $\mathrm{T}_{\mathrm{C}}=$ $0.4 \mathrm{sec}$ is assumed for both Greek records.

In what follows, the predicted and computed damage indices in terms of the equivalent (damage-based) global ductility factor $\mu_{\mathrm{DI}}$ (eq. 5), are compared. Comparisons are limited to a maximum value of $\mu_{\mathrm{DI}}=10$, as values beyond this limit are considered unrealistic. In order to explore the sensi- tivity on the choice of the number $\mathrm{N}$ of the significant halfcycles taken into account for the determination of the 'transversal' sustainability index $\lambda_{1}$, two sets of predictors are presented. One corresponds to $\mathrm{N}=5$ (solid lines) and the other to $\mathrm{N}=9$ (dashed lines). As manifested in the following (Figs. 17-19), in all cases considered, the exact choice of $\mathrm{N}$ does not significantly influence the damage predictions.

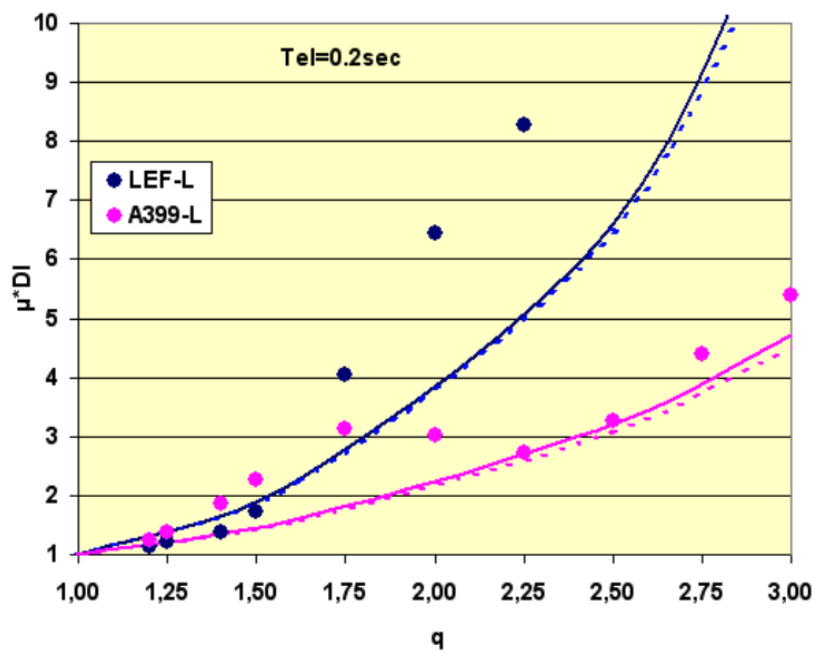

Fig. (17). Computed (circles) and predicted (curves) damage-based ductility factors (eq. 5), for a sdof $\left(\mathrm{T}_{\mathrm{el}}=0.2 \mathrm{sec}, \xi=5 \%\right)$ oscillator subjected to the LEF-L (blue) and scaled A399-L (pink) records.

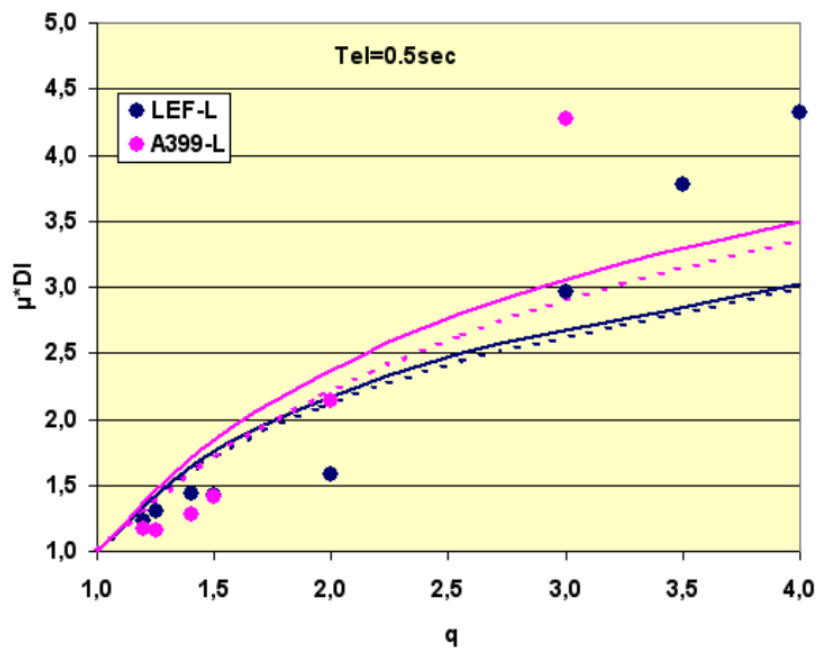

Fig. (18). Computed (circles) and predicted (curves) damage-based ductility factors (eq. 5), for a sdof $\left(\mathrm{T}_{\mathrm{el}}=0.2 \mathrm{sec}, \xi=5 \%\right)$ oscillator subjected to the LEF-L (blue) and scaled A399-L (pink) records.

The performance of the simple damage predictors suggested herein is considered quite promising. They proved capable to not only follow the general trend of the nonlinear dynamic analysis results but also to produce reasonably accurate numerical values of the well-established damage indices.

This is despite the inherent and computational limitations of the methodology. Namely:

(i) The spectral sustainability measures are solely extracted from elastic analyses. 


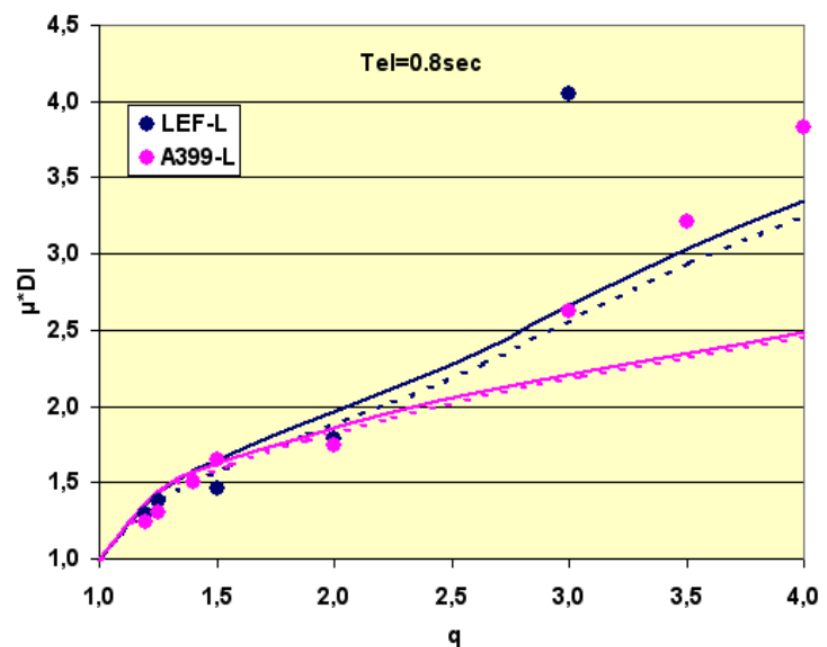

Fig. (19). Computed (circles) and predicted (curves) damage-based ductility factors (eq. 5), for a sdof $\left(\mathrm{T}_{\mathrm{el}}=0.2 \mathrm{sec}, \xi=5 \%\right)$ oscillator subjected to the LEF-L (blue) and scaled A399-L (pink) records.

(ii) Period discretisation affects the accuracy of the computed sustainability indices while the period range limits, set restrictions to large elongation periods $\mathrm{T}_{\mu}$ and corresponding ductility values.

(iii) The transition from an assumed maximum ratio of elongated to elastic periods $T_{\mu} / T_{\text {el }}$ (needed for the computation of the 'horizontal' sustainability index $\lambda_{2}$ ), to the corresponding value of ductility factor $\mu$ and to the related reduction factor $\mathrm{q}$, is based on empirical approximate relationships.

(iv) A simpler version of the horizontal' sustainability index $\lambda_{2}$ is used while the influence of the inelastic (nonhysteretic) response on damping is only indirectly taken into account.

\section{CONCLUSIONS}

In this work, certain useful damage-related properties of 3-D elastic displacement response spectra are identified and valuable information extracted via the introduction of suitable spectral sustainability indices. This information is available within the standard computational scheme for the production of conventional 2-D elastic spectra, but is routinely disregarded. Conversely, it turns out to be extremely useful for both qualitative and quantitative forecast of elastic (fatigue - related) and inelastic damage potential of ground motions.

The two novel spectral sustainability indices $\lambda_{1}$ and $\lambda_{2}$ introduced herein, reflect in a complementary fashion, the two major controlling parameters of the damage potential structural response:

(i) The number of significant response half-cycles ('transversal' sustainability index $\lambda_{1}$ ) which is related to the elastic response characteristics

(ii) The spectral ordinates variation due to the elongation of fundamental elastic period caused by the inelastic response ('horizontal' sustainability index $\lambda_{2}$ ).

The reported results of parametric analyses comprising elasto-plastic oscillators with three elastic periods and a range of reduction factors, subjected to two selected strong ground motion records confirm the strong correlation of the aforementioned indices with the observed response characteristics and the computed damage measures.

Furthermore, the sustainability indices $\lambda_{1}$ and $\lambda_{2}$ were utilised as the basis for the formation of simple yet reliable damage predictors with the ability to both follow the general trend of the nonlinear dynamic analysis and to produce reasonably accurate numerical values of well-established damage indices.

The confirmation of the aforementioned findings for an enriched sample of strong motion records and the applicability of the proposed spectral indices for the damage prediction of more realistic structural systems (such as single and multistorey plane RC frames), is confirmed and will be presented in a forthcoming companion publication. The exploitation of sustainability indices regarding velocity response spectra is the topic of an ongoing investigation.

\section{CONFLICT OF INTEREST}

The author confirms that this article content has no conflicts of interest.

\section{ACKNOWLEDGEMENTS}

The assistance of Mrs. E. Nestoridou (M.Sc. Earthquake Engineering and Seismic-Resistant Structures, Hellenic Open University) for the preparation of this article, is gratefully acknowledged.

\section{REFERENCES}

[1] P.K. Malhotra, "Cyclic-demand spectrum", Earthquake Engineering and Structural Dynamics, vol. 31, pp. 1441-1457, 2002.

[2] A. Teran-Gilmore, and J.O. Jirsa, "A damage model for practical seismic design that accounts for low cycle fatigue", Earthquake Spectra, vol. 21, pp. 803-832, 2005.

[3] J.W. van de Lindt, and G.H. Goh, "Effect of earthquake duration on structural reliability", Engineering Structures, vol. 26, pp. 15851597, 2004.

[4] P. Panyakapo, "Evaluation of site-dependent constant-damage design spectra for reinforced concrete structures", Earthquake Engineering and Structural Dynamics, vol. 33, pp. 1211-1231, 2004.

[5] C.M. Uang, and V.V. Bertero, "Evaluation of seismic energy in structures", Earthquake Engineering and Structural Dynamics, vol. 19, pp. 77-90, 1990.

[6] P.K. Koliopoulos, B.N. Margaris, and N.S. Klimis, "Duration and energy characteristics of greek strong motion records", Journal of Earthquake Engineering, vol. 2, pp. 391-417, 1998.

[7] P.K. Koliopoulos, and E. Kirtas, "Plastic Energy Demand of the September 1999 Athens Earthquake", in Proceedings of the $12^{\text {th }}$ European Conference on Earthquake Engineering, 2002, CD ROM Paper No. 220.

[8] M.C. Chapman, "On the use of elastic energy for seismic hazard analysis", Earthquake Spectra, vol. 15, pp. 607-635, 1999.

[9] E. Safak, "3D Response spectra: a method to include duration in response spectra", in Proceedings of the $11^{\text {th }}$ European Conference on Earthquake Engineering, 1998.

[10] P.K. Koliopoulos, and B.N. Margaris, "The 1999 Athens (Greece) Earthquake: Energy and Duration - Related Response Spectral Characteristics of Different Site Conditions", in Proceedings of the $4^{\text {th }}$ Int. Conf. on Recent Advances in Earthquake Engineering and Soil Dynamics, 2001, Paper No. 10.31.

[11] J.W Baker, and C.A. Cornell, "Vector-valued intensity measures incorporating spectral shape for prediction of structural response", Journal of Earthquake Engineering, vol. 12, pp. 534-554, 2008

[12] E. Bojórquez and I. Iervolino, "A Spectral Shape-based Scalar Ground Motion Intensity Measure for Maximum and Cumulative 
Structural Demands", in Proceedings of the $14^{\text {th }}$ European Conference on Earthquake Engineering (14ECEE), 2010.

[13] P.K. Koliopoulos, "3-D response spectra of selected Greek strong motion records", Internal Report (in Greek), Civil Engineering Department, Technological Educational Institution of Serres, May 2012.

[14] P.K. Koliopoulos, "Damage predictors based on spectral sustainability indices of selected Greek strong motion records", Internal Report (in Greek), Civil Engineering Department, Technological Educational Institution of Serres, September 2013.

[15] P. Gulkan, and M.A. Sozen, "Inelastic response of reinforced concrete structures to earthquake motions", ACI Journal, vol. 71, pp. 604-610, 1974.

[16] B. Borzi, A.S. Elnashai, E. Faccioli, G. Calvi, and J.J. Bommer, "Inelastic spectra and ductility-damping relationships for displacement-based seismic design", ESEE Research Report No. 98-4, Imperial College, 1998.

[17] Y.J. Park, and A.H-S. Ang, "Mechanistic seismic damage model for reinforced concrete", Journal of Structural Engineering, ASCE, vol. 111, pp. 722-739, 1985

[18] Y.J. Park, A.H-S. Ang, and Y.K. Wen, "Damage - limiting aseismic design of buildings", Earthquake Spectra, vol. 3, pp. 1-26, 1987.
[19] E. Cosenza, and G. Manfredi, "Damage indices and damage measures", Progress in Structural Engineering and Materials, vol. 2, pp. $50-59,2000$.

[20] I.G. Craifaleanu, and I.S. Borcia, "Damage Index vs. Instrumental Intensity: A Comparison of Two Different Approaches in Seismic Damage Assessment", in Proceedings of the $15^{\text {th }}$ World Conference on Earthquake Engineering, 2012.

[21] P. Fajfar, "Equivalent ductility factors, taking into account lowcycle fatigue", Earthquake Engineering \& Structural Dynamics, vol. 21, pp 837-848, 1992.

[22] M. Trueb, Y. Belmouden, and P. Lestuzzi, "Displacement ductility demand and strength reduction factors for rocking structures", WIT Transactions on The Built Environment, vol. 93, pp. 195-204, 2007.

[23] I. Taflampas, and I.N. Psycharis, "Investigation of the Effect of the Ground Motion Characteristics on the Ry-M Relation for the Inelastic Response of Sdof Structures", In Proceedings of the $14^{\text {th }}$ World Conference in Earthquake Engineering, 2008.

[24] P. Fajfar, "A nonlinear analysis method for performance based seismic design", Earthquake Spectra, vol. 16, pp. 573-592, 2000.

Received: November 11, 2013

Revised: January 30, 2014

Accepted: January 30, 2014

(C) P.K. Koliopoulos; Licensee Bentham Open.

This is an open access article licensed under the terms of the Creative Commons Attribution Non-Commercial License (http://creativecommons.org/licenses/by-nc/3.0/) which permits unrestricted, non-commercial use, distribution and reproduction in any medium, provided the work is properly cited. 